\title{
Recommendation decision-making algorithm for sharing accommodation using probabilistic hesitant fuzzy sets and bipartite network projection
}

\author{
Qian $\mathrm{Cao}^{1} \cdot$ Xiaodi Liu ${ }^{1} \cdot$ Zengwen $\mathrm{Wang}^{2} \cdot$ Shitao Zhang ${ }^{1} \cdot$ Jian $\mathrm{Wu}^{1}$
}

Received: 26 January 2020 / Accepted: 4 April 2020 / Published online: 22 April 2020

(c) The Author(s) 2020

\begin{abstract}
In recent years, with the uninterrupted development of sharing accommodation, it not only caters to the diversified accommodation of tourists, but also takes an active role in expanding employment and entrepreneurship channels, enhancing the income of urban and rural residents, and promoting the revitalization of rural areas. However, with the continuous expansion of the scale of sharing accommodation, it is fairly complicated for users to search appropriate services or information. The decision-making problems become more and more complicated. Hence, a probabilistic hesitant fuzzy recommendation decision-making algorithm based on bipartite network projection is proposed in this paper. First of all, combining the users' decision-making information and the experts' evaluation information, a bipartite graph connecting users and alternatives is established. Then, the satisfaction degree of probabilistic hesitant fuzzy element is defined. Besides, the recommended alternative is obtained by the allocation of resources. Finally, a numerical case of Airbnb users is given to illustrate the feasibility and effectiveness of the proposed method.
\end{abstract}

Keywords Bipartite network projection · Probabilistic hesitant fuzzy set · Satisfaction degree $\cdot$ Recommendation decisionmaking $\cdot$ Sharing accommodation

\section{Introduction}

With the rapid development of emerging technologies and continuous upgrade of municipal and rural tourism consumption and services, sharing accommodation has gradually gone into people's sight. Figure 1 indicates the high growth of sharing accommodation orders in some Chinese cities. Shar-

Xiaodi Liu

1xy1160@163.com

Qian Cao

cq0628@163.com

Zengwen Wang

wzwnjing@163.com

Shitao Zhang

zhangshitao1980@126.com

Jian Wu

wujian950304@163.com

1 School of Mathematics and Physics, Anhui University of Technology, Ma'anshan 243002, China

2 Researching Center of Social Security, Wuhan University, Wuhan 430072, Hubei, China ing accommodation has characteristics of diversified supply subjects and service contents and socialized user experience, which can meet diverse accommodation need. At the same time, sharing accommodation can reduce the information asymmetry and transaction risk between the landlords and the tenants. It offers a better service experience to landlords [1]. Not only that the economic development of sharing accommodation plays a positive role in expanding employment and entrepreneurship channels, increasing the income of urban and rural residents, and helping rural revitalization [2]. In 2017, Airbnb created over 20,000 employment opportunities in Beijing and Shanghai. According to a survey of Airbnb's domestic landlords, landlords can significantly improve their daily living standards by house sharing income. More than that, Airbnb participates in the innovative tourism targeted poverty alleviation project, explores new models for rural housing poverty relief, and helps rural poor families get rid of poverty. Sharing accommodation has made great contributions to social development.

The report on development of China's sharing accommodation shows that the market scale of sharing accommodation industry will maintain a growth rate of $50 \%$ in the next 
Fig. 1 The growth of sharing accommodation orders in some Chinese cities

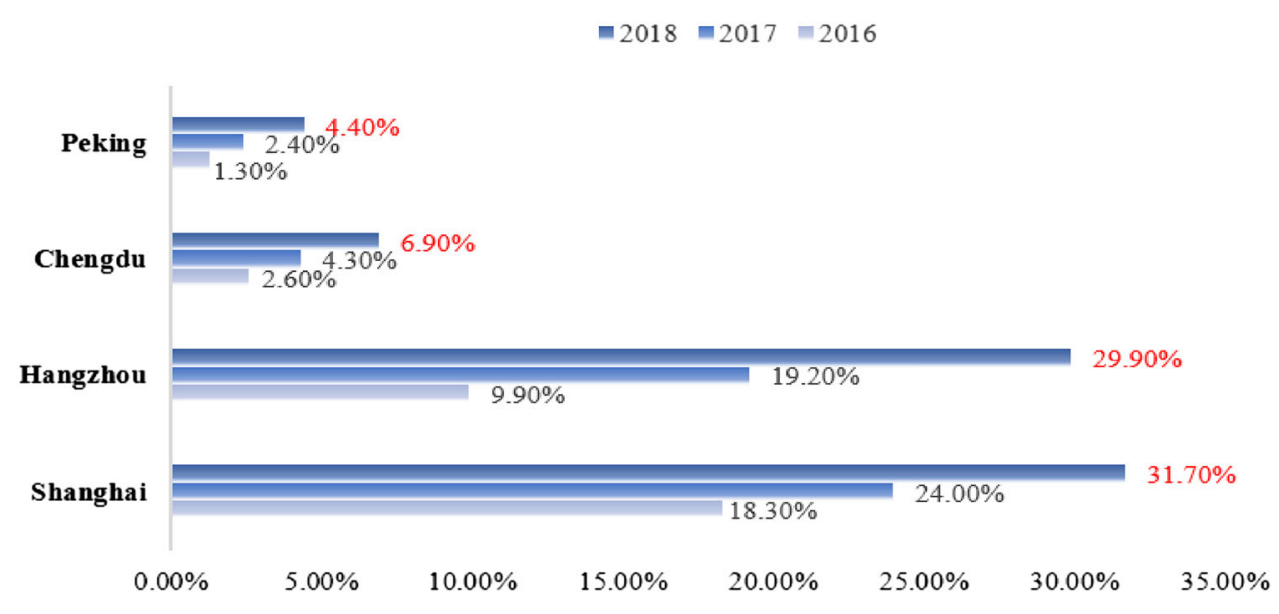

3 years, as well as the number of online housing resource will get an increase [1]. In such a trend, it is more difficult to obtain the required housing resource information by users themselves. This situation is bad for the development of sharing accommodation. Therefore, it is worth thinking about how to response to this trend and provide accurate accommodation information for users.

Recommender systems are used as decision support systems to overcome information overload in online environments [3]. Collaborative filtering $(\mathrm{CF})$ [4] recommender system is one of the most popular types of recommender systems [5]. It is mainly used as information retrieval system based on past users' activities and ratings on the items. Content-based recommendation is the continuation and development of CF recommendation. It does not rely on users' historical activities and ratings on the items, but calculates the similarity degree between users based on product content information [6]. Besides, according to online review information, scholars have put forward some recommendation systems based on users' historical information [7, 8]. By extracting the online review information, the text information needs to be transformed into computable data, and it will inevitably lead to the loss of information. Therefore, it is necessary to propose a new recommendation method to solve the existed problems.

Without considering the content characteristics of users and products, the network-based recommendation algorithm directly regards them as abstract nodes. Owing to the relatively clear data structure, bipartite networks have attracted widespread attention. They have been successively applied to cluster analysis [9-11], pattern recognition [12-14], recommender systems [15-18], and other fields. Zhou et al. presented a bipartite network algorithm based on resource-allocation dynamics [19]. The similarity degree among homogeneous nodes is utilized to implement personal recommendation for users. Subsequently, Liu et al. analyzed the similarities and differences between weighted and unweighted bipartite graph networks by combining collabo- rative filtering with network reasoning [20]. It is concluded that recommendation accuracy of the weighted bipartite graph network is higher than that of the unweighted one under the same amount of calculations. The attendant problem is how to determine the weights of adjacent edge for improving algorithm accuracy. Wang et al. introduced a half cumulative distribution method to normalize the weights of adjacent edges, and mapped the original scores to the probability of users' preference [21]. Pan et al. defined the weights of edges based on the distribution of degree between user and object [22]. Then, they applied the weights of edges in the quality diffusion to improve the accuracy of recommendation algorithm. Li et al. used monotonic saturation function to calculate the weights of edges [23]. An approach to calculate the weights which is based on balance factor was proposed by Song et al. [24]. In the existed methods, the connection degree and the distribution of two kinds of nodes are two commonly used tools to calculate the weights of adjacent edges, which are based on users' ratings or historical usage. As the amount of information increases, users are accustomed to utilize key words or attributes to filter information and services. Besides, when we determine the recommended content based on the users' historical data, it will not only focus on the direct evaluation on object, but also analyze the root cause of users' choices, because users pay attention to the characteristics of the content, which is one of the research contents in this paper.

Users often passively accept recommendations rather than making their own decisions; that is to say, the information service platform recommends information or services to users depending on their historical data. In some cases, decisionmakers are not always able to obtain "certain information" when evaluating alternatives because of the diversification of users' demands. How to depict the evaluation information more reasonably is another urgent problem. To describe the uncertainty, Zadeh proposed the concept of fuzzy sets $[25,26]$. With the continuous process of human practice and increasingly complicated decision-making environment, 
some extended forms of fuzzy sets have been proposed to model uncertainty, such as the interval-valued fuzzy sets [27], the intuitionistic fuzzy sets [28-30], the type-2 fuzzy sets [31, 32], the fuzzy multi-sets [33], the Pythagorean fuzzy sets [34, 35], the hesitant fuzzy sets (HFSs) [36, 37], the dual hesitant fuzzy soft sets [38], the probabilistic hesitant fuzzy sets [39], and so on. Since the hesitant fuzzy set was proposed, it has been widely applied in many fields, such as decisionmaking [40-43], emergency management [44, 45], online reviews [46], supply chain management [47], and so on. When defining the membership of an element, the difficulty of establishing the membership degree is not because we have a margin of error [as in intuitionistic fuzzy sets (IFSs)], but because we have a set of possible values [36]. For example, a decision organization that contains ten experts is authorized to assess the degree that an alternative should satisfy an attribute. Some of them think that 0.9 is most appropriate and the rest insist that it is 0.5 , and these two different groups of experts cannot persuade each other. It is noted that the HFE $\{0.5,0.9\}$ can describe the above situation more objectively than the fuzzy number 0.5 (or 0.9 ) or the interval-value fuzzy set $[0.5,0.9]$. Therefore, HFSs can express the decisionmakers' judgments more informative and reliable in this case. Probabilistic hesitant fuzzy set (PHFS), as an extension of HFS, not only contains different membership degrees, but also gives the occurrence probabilities associated with membership degrees, which reserves more original information than HFSs. Therefore, it can fully describe the uncertainty of decision-making information, which has attracted more and more scholars' attention. Zhou and Xu defined the basic operation of PHFSs [48]. Furthermore, the operation rules and aggregation operators of PHFSs are defined by Zhang et al. [49]. Subsequently, it was applied to various fields such as decision-making [50, 51], supply chain management [52], project investment [53], and so on. Due to the uncertainty of users' recommendation content, PHFS which can be thought as an effective tool for modeling the uncertainty is utilized to present the evaluation information in this paper. Considering those advantages of PHFS, we introduce it into the bipartite network projection, and establish a novel bipartite graph network which integrates users' decision information and experts' evaluation information simultaneously.

In addition, the satisfaction degree of PHFE is proposed, and the weights of adjacent edges are determined in this paper. We combine bipartite network with PHFS to address complex decision-making problems in recommendation system. The main contributions and innovation of this paper are mainly reflected in the following aspects:

(1) Recommendation system is one of the most effective ways to overcome information overload. A novel recommender system is proposed to aid decision-making in this paper. It could assist us in making decisions with huge information.

(2) Based on bipartite network, a recommendation decision-making method is proposed. To measure the degree of diversification for users' demands, probabilistic hesitant fuzzy set is used to model the uncertainty, and thus, a probabilistic hesitant fuzzy bipartite network is established in this paper to aid decision-making.

(3) The weights of adjacent edges play a vital role in bipartite network projection. Then, a probabilistic hesitant fuzzy satisfaction degree is presented to calculate the weight of adjacent edges. Our method expresses the uncertainty flexibly, and, at the same time, greatly improves the accuracy of recommendation system.

(4) The proposed method can address a series of problems such as information overloading, ambiguity of user's requirement, and so on, and, thus, provide effective measures for the development of sharing economy.

The remaining sections of this paper are organized as follows. Some basic concepts related to PHFS and bipartite network projection are introduced in Sect. 1. In Sect. 2, we establish a bipartite graph connecting users and alternatives. Then, the satisfaction degree of probabilistic hesitant fuzzy element is defined. In Sect. 3, an illustrative example of recommending a hotel for Airbnb user is used to explain the feasibility and effectiveness of the proposed method. And conclusions are drawn in Sect. 4.

\section{Preliminaries}

Some basic concepts related to PHFS and the preliminaries used throughout this paper are introduced in this section.

\section{PHFSs}

To model preferences of decision-makers, Zhu defined PHFSs as follows [39].

Definition 1 Let $X=\left\{x_{1}, x_{2}, \ldots, x_{n}\right\}$ be a fixed set, a PHFS on $X$ is defined in terms of a function $h_{x}\left(p_{x}\right)$ that when applied to $X$ returns a subset of $[0,1]$, which is expressed as:

$H=\left\{\left\langle x, h_{x}\left(p_{x}\right)\right\rangle \mid x \in X\right\}$,

where the function $h_{x}\left(p_{x}\right)$ is a set of some values in $[0,1]$. $h_{x}$ denotes the possible membership degrees of the element $x$ in $X$ to the set $H$, and $p_{x}$ is a set of probabilities associated with $h_{x} \cdot h_{x}\left(p_{x}\right)$ is called probabilistic hesitant fuzzy element (PHFE). For convenience, we express $h_{x}\left(p_{x}\right)$ as $h(p)$ :

$h(p)=h_{x}\left(p_{x}\right)=\left\{\gamma_{l}\left(p_{l}\right), l=1,2, \ldots,|h(p)|\right\}$,

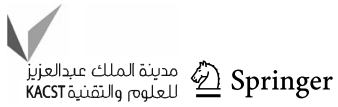




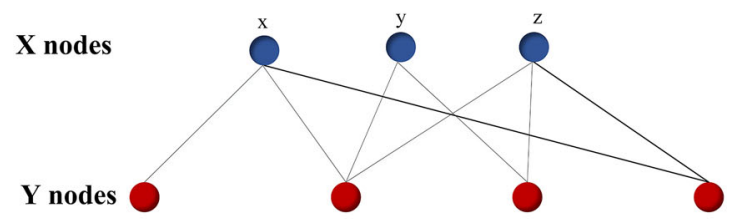

(a)

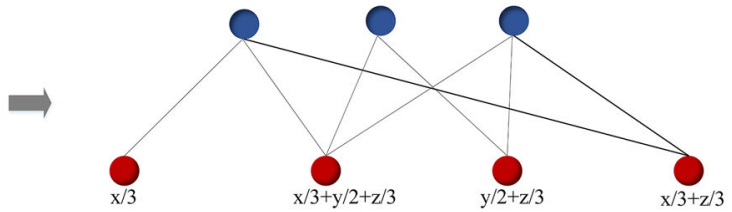

(b)

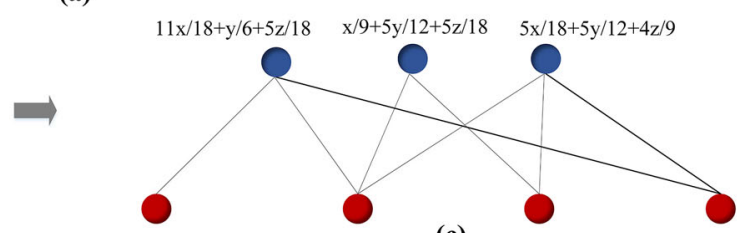

(c)

Fig. 2 Bipartite projection network

where $p_{l}$ is the probability of the membership degree of $\gamma_{l}$, $\gamma_{l}\left(p_{l}\right)$ is called PHFE, $|h(p)|$ is the number of all different membership degrees, and $\sum_{l=1}^{|h(p)|} p_{l}=1$.

To compare PHFEs, the score function and the deviation function of PHFEs are defined as follows.

Definition 2 Let $h(p)$ be a PHFE. Then:

$E(h(p))=\sum_{l=1}^{|h(p)|} \gamma_{l} \times p_{l}$,

is called the score function of the $h(p)$.

Definition 3 Let $h(p)$ be a PHFE. Then,

$D(h(p))=\sum_{l=1}^{|h(p)|}\left(p_{l} \gamma_{l}-E(h(p))\right)^{2}$,

is called the deviation function of $h(p)$.

\section{Bipartite network projection and personality recommendation}

In the bipartite graph network, there are two types of node sets: $X$ nodes and $Y$ nodes. Arbitrary two nodes in the same set are not directly connected. If there is a connection between two nodes in different sets, there must be an association or relationship between the two nodes. For different models, the nature, the content, and the sense of relationships between nodes are different. The bipartite graph network contains a wealth of information, which has great significance both in theoretical research and practical applications. It has been used to investigate the relationship between nodes in the same set by projection compression.

\section{Bipartite network projection}

Based on resource allocation, Zhou et al. [19] proposed a bipartite projection network, and analyzed the inherent rela- tionship between nodes in the same set by correlating the nodes in two different sets.

For a given bipartite graph network, as shown in Fig. 2a, the internal relationship between nodes can be studied by two-step projection compression: first, the resources flow from $X$ nodes to $Y$ nodes. The resources obtained by $Y$ nodes are shown in Fig. 2b. Then, resources flow back to $X$ nodes. The resources on $X$ nodes are shown in Fig. 2c. In this case, the resources of nodes are equally allocated to their adjacent edges.

The final resources located in those three nodes are denoted by $x^{\prime}, y^{\prime}$, and $z^{\prime}$, which can be expressed by:

$$
\left(\begin{array}{l}
x^{\prime} \\
y^{\prime} \\
z^{\prime}
\end{array}\right)=\left(\begin{array}{ccc}
11 / 18 & 1 / 6 & 5 / 18 \\
1 / 9 & 5 / 12 & 5 / 18 \\
5 / 18 & 5 / 12 & 4 / 9
\end{array}\right)\left(\begin{array}{l}
x \\
y \\
z
\end{array}\right) .
$$

Here, the element in the $i$ th row and $j$ th column represents the fraction of resource that the $j$ th node of $X$ transfers to the $i$ th node. The larger the value is, the closer the relationship between the two nodes is.

However, in real life, the attribute weights are not always the same. The definition of bipartite projection with general weight is given as below [19].

Suppose $G(X, Y, \Gamma)$ is a general bipartite network, where $\Gamma$ is the set of edges. $X$ is the set of upper nodes, $Y$ is the set of lower nodes, and the nodes in $X$ and $Y$ are denoted by $x_{1}, x_{2}, \ldots, x_{n}$ and $y_{1}, y_{2}, \ldots, y_{m}$, respectively. We first assume that the connection of nodes only exists between the different sets, and it does not exist in the same set. The initial resource located on $x_{i}$ node meets $f\left(x_{i}\right) \geq 0$.

All the resources in $X$ flow to $Y$, and the resource of the $y_{l}$ node is denoted as:

$$
f\left(y_{l}\right)=\sum_{i=1}^{n} \frac{a_{i l} f\left(x_{i}\right)}{k\left(x_{i}\right)},
$$


where $k\left(x_{i}\right)$ denotes the degree of $x_{i}$ and $a_{i l}$ is a characteristic function of set $\Gamma=\left\{o(i, l) \mid x_{i} \in X, \quad y_{l} \in Y\right\}$ :

$a_{i l}=\left\{\begin{array}{l}1, o(i, l) \in \Gamma \\ 0, \text { otherwise }\end{array}\right.$.

Then, all the resources flow back to $X$, and the final resource of node $x_{i}$ is:

$f^{\prime}\left(x_{i}\right)=\sum_{l=1}^{m} a_{i l} f\left(y_{l}\right) / k\left(y_{l}\right)=\sum_{l=1}^{m} \frac{a_{i l}}{k\left(y_{l}\right)} \sum_{j=1}^{n} \frac{a_{j l} f\left(x_{j}\right)}{k\left(x_{j}\right)}$.

This can be expressed as:

$f^{\prime}\left(x_{i}\right)=\sum_{j=1}^{n} w_{i j} f\left(x_{j}\right)$

where

$w_{i j}=\frac{1}{k\left(x_{j}\right)} \sum_{l=1}^{m} \frac{a_{i l} a_{j l}}{k\left(y_{l}\right)}$.

Here, $k\left(x_{i}\right)$ denotes the degree of $x_{i}$ and $k\left(y_{l}\right)$ denotes the degree of $y_{l}$.

\section{Personal recommendation based on weighted bipartite network projection}

Wang et al. [21] proposed a weighted bipartite network projection for personalized recommendations.

In a bipartite network $G(U, A, \Gamma), \Gamma$ is the set of edges, $U$ is the upper nodes set for users, and $A$ is the lower nodes set for alternatives. The nodes in $U$ and $A$ are denoted by $U_{1}, U_{2}, \ldots, U_{n}$ and $A_{1}, A_{2}, \ldots, A_{m}$, respectively. The connection exists only between $U$ and $A$, and it is not directly connected in the same set. For user $U_{i}$, the weighted networkbased method starts by assigning the initial resource for alternatives. If the alternative connects with the user, it would be assigned a unit resource as its initial resource, otherwise zero. The resource-allocation process includes two stages:

(1) The resource flows from $A$ to $U$.

The resource of alternative $A_{i}$ is assigned to its neighbor users according to the ratio of the edge weights. The total resources of user $U_{k}$ are as follows:

$g\left(U_{k}\right)=w_{k i} f\left(A_{i}\right)$.

Here, $g\left(U_{k}\right)$ is the resource that user $U_{k}$ would obtain from its neighbor alternatives; $f\left(A_{i}\right)$ is the initial resource for alternative $A_{i}$.
(2) The resource flows from $\mathrm{U}$ to $\mathrm{A}$.

Similarly, the finally resources that alternative $A_{i}$ obtained from its connected users across the process of allocation are as follows:

$f^{\prime}\left(A_{i}\right)=w_{k i} g\left(U_{k}\right) / \sum_{k=1}^{s} w_{k i}$.

By plugging Eqs. (11) into (12), $f^{\prime}\left(A_{i}\right)$ can be expressed by $f^{\prime}\left(A_{i}\right)=\rho_{k i} f\left(A_{i}\right)$, where $\rho_{k i}=w_{k i}^{2} / \sum_{k=1}^{s} w_{k i}$, and $\rho_{k i}$ denotes the similarity coefficient of user $U_{k}$ and user $U_{i}$. The greater the similarity coefficient between user $U_{k}$ and user $U_{i}$ is, the more possibility they choose the same alternatives. Then, the alternative can be recommended for the user $U_{k}$ based on the choice of user $U_{i}$.

\section{Recommendation decision-making algorithm based on PHFSs and bipartite network projection}

\section{The probabilistic hesitant fuzzy satisfaction degree}

For a probabilistic hesitant fuzzy multi-attribute decisionmaking problem, there is a set of $n$ alternatives $A=$ $\left\{A_{1}, A_{2}, \ldots, A_{n}\right\}$, and a set of $m$ attributes $C=$ $\left\{C_{1}, C_{2}, \ldots, C_{m}\right\}$. Experts evaluate the alternatives for each attribute, and the set of all possible evaluations for an alternative $A_{i}(i=1,2, \ldots, n)$ under the attribute $C_{j}$ $(j=1,2, \ldots, m)$ can be considered as a PHFE $h_{i j}\left(p_{i j}\right)$. Thus, based on the above description, we can construct a probabilistic hesitant fuzzy decision matrix $\Theta$ as follows:

$\Theta=\left[\begin{array}{cccc}h_{11}\left(p_{11}\right) & h_{12}\left(p_{12}\right) & \cdots & h_{1 m}\left(p_{1 m}\right) \\ h_{21}\left(p_{21}\right) & h_{22}\left(p_{22}\right) & \cdots & h_{2 m}\left(p_{2 m}\right) \\ \vdots & \vdots & \ddots & \vdots \\ h_{n 1}\left(p_{n 1}\right) & h_{n 2}\left(p_{n 2}\right) & \cdots & h_{n m}\left(p_{n m}\right)\end{array}\right]$.

To measure the satisfaction degree of alternatives better and understand user's requirement, we define the satisfaction degree of PHFEs which is inspired by the idea of Liu et al. [54].

Definition 4 Let $h(p)=\left\{\gamma_{l}\left(p_{l}\right), l=1,2, \ldots\right.$, $|h(p)|$ and $\left.\sum_{l=1}^{|h(p)|} p_{l}=1\right\}$ be a PHFE. We define the satisfaction degree of $h(p)$ as:

$\varphi(h(p))=\frac{E(h(p))}{1+D(h(p))}=\frac{E(h(p))}{1+\sum_{l=1}^{|h(p)|}\left(p_{l} \gamma_{l}-E(h(p))\right)^{2}}$. 
Here, $E(h(p))$ is the score function and $D(h(p))$ is the deviation function of $h(p)$, which can be calculated by Eqs. (2) and (3), respectively.

The decision-making information can be utilized to measure the satisfaction of alternatives more completely by considering the score function and deviation function simultaneously. The larger the $E(h(p))$ is, the higher the satisfaction is. While the deviation function can reflect the level of disagreement among the decision-makers. Intuitively, the smaller the deviation $D(h(p))$ is, the higher the satisfaction degree is.

\section{The recommendation decision-making method}

In the traditional bipartite graph recommendation system, the evaluation value of user is represented as crisp number. However, in the actual decision-making, users are often hesitant to express their preferences for alternatives. To make the recommendation content closer to the users' preferences, a bipartite network which considers the user's demand for product attributes and the satisfaction degree of the recommendation content is established. The satisfaction degree is used to determine the adjacent edge weight of the bipartite network. Combining probabilistic hesitant fuzzy information with the bipartite graph network, a recommendation decision-making algorithm is proposed.

Assume that $A=\left\{A_{1}, A_{2}, \ldots, A_{n}\right\}$ is the set of alternative, $C=\left\{C_{1}, C_{2}, \ldots, C_{m}\right\}$ is the set of attribute, $U=$ $\left\{U_{1}, U_{2}, \ldots, U_{\mathrm{s}}\right\}$ is the set of user, and $\Gamma$ is the set of adjacent edge. According to users' requirement, the evaluation values for alternatives take the form of PHFEs. Then, the probabilistic hesitant fuzzy decision-making matrix is expressed as follows:

$$
\Theta=\left[\begin{array}{cccc}
h_{11}\left(p_{11}\right) & h_{12}\left(p_{12}\right) & \cdots & h_{1 m}\left(p_{1 m}\right) \\
h_{21}\left(p_{21}\right) & h_{22}\left(p_{22}\right) & \cdots & h_{2 m}\left(p_{2 m}\right) \\
\vdots & \vdots & \ddots & \vdots \\
h_{n 1}\left(p_{n 1}\right) & h_{n 2}\left(p_{n 2}\right) & \cdots & h_{n m}\left(p_{n m}\right)
\end{array}\right]
$$

The satisfaction degree of PHFE can be calculated by Eq. (14), and then, the probabilistic hesitant fuzzy satisfaction degree matrix $\Psi$ can be obtained:

$$
\Psi=\left[\begin{array}{cccc}
\varphi\left(h_{11}\left(p_{11}\right)\right) & \varphi\left(h_{12}\left(p_{12}\right)\right) & \cdots & \varphi\left(h_{1 m}\left(p_{1 m}\right)\right) \\
\varphi\left(h_{21}\left(p_{21}\right)\right) & \varphi\left(h_{22}\left(p_{22}\right)\right) & \cdots & \varphi\left(h_{2 m}\left(p_{2 m}\right)\right) \\
\vdots & \vdots & \ddots & \vdots \\
\varphi\left(h_{n 1}\left(p_{n 1}\right)\right) & \varphi\left(h_{n 2}\left(p_{n 2}\right)\right) & \cdots & \varphi\left(h_{n m}\left(p_{n m}\right)\right)
\end{array}\right] .
$$

The standard frequency matrix $\Omega$ of the user's requirement for attributes can be calculated as below:

$\Omega=\left[\begin{array}{cccc}t_{11} & t_{12} & \cdots & t_{1 m} \\ t_{21} & t_{22} & \cdots & t_{2 m} \\ \vdots & \vdots & \ddots & \vdots \\ t_{s 1} & t_{s 2} & \cdots & t_{s m}\end{array}\right]$

where $\sum_{j=1}^{m} t_{k j}=1,(k=1,2, \ldots, s)$.

Thus, combining matrix $\Psi$ and matrix $\Omega$, we could acquire the set of adjacent edge $o(i, k)$ between user $U_{k}$ $(k=1,2 \ldots, s)$ and alternative $A_{i}(i=1,2, \ldots, n)$ :

$\Gamma=\left\{o(i, k) \mid\right.$ for every $t_{j k} \neq 0$, we have $\left.\varphi_{i j} \neq 0, j=1,2, \ldots m\right\}$.

Then, the weight of adjacent edge $\phi_{k i}$ between alternative $A_{i}(i=1,2, \ldots, n)$ and user $U_{k}(k=1,2 \ldots, s)$ can be calculated by the following equation:

$\phi_{k i}=\sum_{j=1}^{m} t_{k j} \varphi_{i j}$.

In the recommendation decision-making process, the recommended user $U_{\mathrm{r}}$ is set to gray, while the initial resource of the alternative $A_{\mathrm{c}}$ connected to the recommended user is set to 1 , otherwise 0 . The projection steps are shown as follows:

(1) The resource flows from $A$ to $U$, and the resource of user $U_{k}$ is:

$g\left(U_{k}\right)=w_{k i} f\left(A_{i}\right)$

Let

$g\left(U_{h}\right)=\max g\left(U_{k}\right),(k=1,2, \ldots, s$ and $k \neq r)$,

where $w_{k i}=\phi_{k i} / \sum_{i=1}^{n} \phi_{k i}$, and $f\left(A_{i}\right)$ is the initial resource of alternative $A_{i}$. The resource of user $U_{k}$ is obtained from its neighbor edge.

(2) The resource flows from $U$ to $A$, and the resources owned by alternative $A_{i}$ are $f^{\prime}\left(A_{i}\right)$.

$f^{\prime}\left(A_{i}\right)=\rho_{k i} f\left(A_{i}\right)$.

Let

$F\left(A_{o}\right)=\max f^{\prime}\left(A_{i}\right),(i=1,2, \ldots, n$ and $i \neq c)$, 
where $\rho_{k i}=w_{k i}^{2} / \sum_{k=1}^{s} w_{k i}$, and $\rho_{k i}$ denotes the similarity degree between user $U_{k}$ and user $U_{i}$. The higher the similarity degree is, the more similar the preferences for alternatives are. Thus, we could recommend alternative $A_{o}$ for user $U_{r}$ by analyzing the preference of user $U_{h}$.

\section{The steps of the proposed recommendation decision-making algorithm}

Based on the above analysis, a recommendation decisionmaking algorithm based on probabilistic hesitant fuzzy bipartite graph network is summarized as below:

Step 1. According to users' requirements for each attribute $C_{j}(i=1, \ldots, m)$, we can obtain the corresponding frequency matrix $\Omega$. Experts evaluate alternatives $A_{i}$ $(i=1,2, \ldots, n)$, and the corresponding probability hesitant fuzzy evaluation matrix $\Theta$ can be obtained.

Step 2. Calculate the satisfaction degree of PHFE in $\Theta$ by Eq. (14) and the corresponding probabilistic hesitant fuzzy satisfaction degree matrix $\Psi$ can be derived.

Step 3. Combining matrix $\Psi$ and matrix $\Omega$, the set $\Gamma$ of adjacent edge $o(i, k)$ between user $U_{k}(k=1,2 \ldots, s)$ and alternative $A_{i}(i=1,2, \ldots, n)$ can be obtained by Eq. (18). The adjacent edge weights $\phi_{k i}(k=1, \ldots, s, i=i, \ldots, n)$ of bipartite networks are calculated by Eq. (19).

Step 4. The recommended user $U_{r}$ is set to gray, while the initial resource of the alternative $A_{\mathrm{c}}$ connected to the recommended user is set to 1 , otherwise 0 . Calculate $g\left(U_{h}\right)$ and $F\left(A_{o}\right)$ by Eqs. (21) and (23), respectively.

Step 5. Output the recommended alternative $A_{o}$. Therefore, it is prior to recommend alternative $A_{o}$ for user $U_{\mathrm{r}}$ by analyzing the preference of user $U_{h}$.

Step 6. End.

To facilitate the reader's understanding, the flowchart of the algorithm is shown in Fig. 3.

\section{Illustrative example}

Airbnb is one of the leading rental communities, where users can post or search vacation rental information and complete online booking programs via its web or mobile apps. It is convenient to obtain house information on Airbnb mobile application. Then, an eligible list will be shown for users on the website after inputting destination, dates, guests' number, etc. It can be further set property prices, community facilities, and other search results for secondary screening. By clicking on a link in the message, user could obtain more detailed information, including description, photos, and reviews of previous guests. The search page of Airbnb mobile software is shown in Fig. 4.

In 2015, Airbnb settled in China. Due to the fierce competition in the Chinese market, it did not get the expected growth

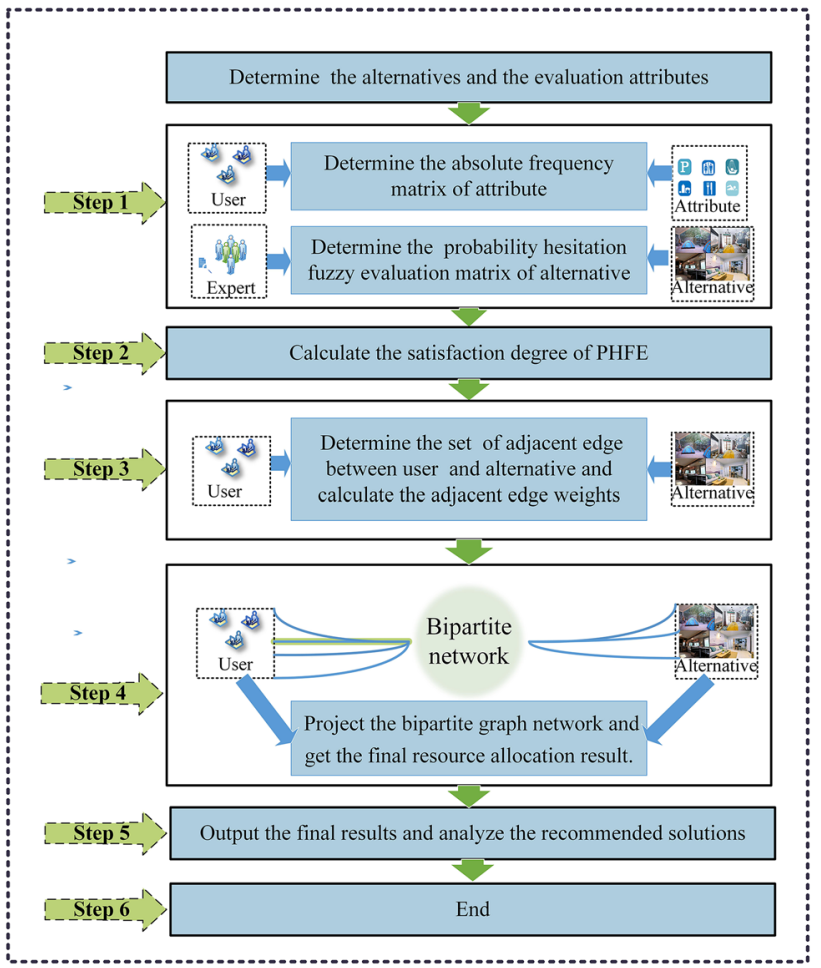

Fig. 3 The flowchart of the algorithm

in time. To get a breakthrough in the Chinese market, Airbnb needs to carry out adequate public relations activities and adopts precise market positioning and marketing strategies [55]. According to the report released by Airbnb in 2019 [56], the disposable income of residents has been continuously increasing in recent years and the consumption structure of residents has been gradually optimized. Moreover, the consumption of education and entertainment continues to grow. In recent years, tourism market presents sound and rapid development momentum, with 4.0 domestic per capita trips and 10.7 outbound trips per 100 people. With comprehensive penetration of the Internet, people's lifestyle and consumption habits are constantly changing. At the same time, the tourism market is increasingly delivered over the Internet.

The millennials (who were born in 1982-2000) constitute nearly $80 \%$ of online travelers, and become the main force of tourism market. They pursue a high-quality and fashion lifestyle, but also explore the unknowns without neglecting to interact with family members. Nearly half of millennials have a higher expense on accommodation than before. In addition, the pursuit of comfortable sleep and the general relaxation environment like home and a colorful accommodation experience will greatly enhance travel happiness. With the development of the sharing economy and the popularity of sharing accommodation, the specialty home stays and the short-term rentals are ever more popular among millennial travelers. However, it is hard to obtain an accurate house

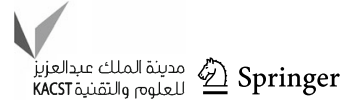




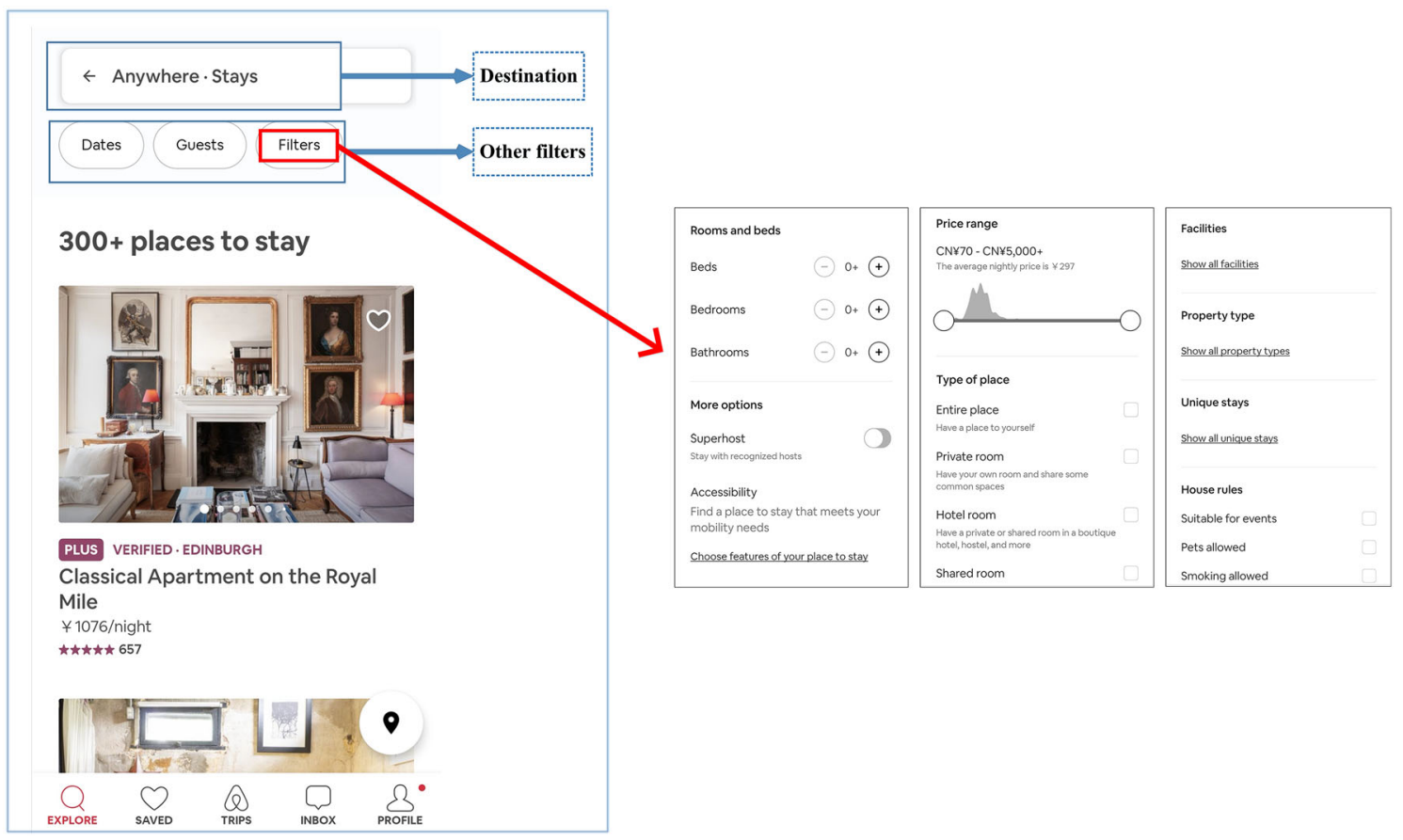

Fig. 4 The search page of Airbnb mobile application

information in travel. Hence, we propose a method to recommend accommodation for Airbnb users in this paper.

A handful of studies on tourists' motivations for choosing Airbnb have been investigated. Quinby and Gasdia found that home amenities and space were the two main motivations for users to choose sharing accommodation [57]. Several studies show that price (or economic benefits) has been recognized sometimes as the most important factor [57-59]. Nowak et al. considered location to be the second most important factor [59]. Besides, some scholars analyzed the user's intention of using Airbnb [60-62]. According to the above literatures and attributes collected from Airbnb community (https://www. airbnb.cn), factors influencing user's decision are shown in Table 1.

Five different houses near Nanjing Confucius Temple are to be evaluated (as shown in Table 2). Four users who have stayed at the five houses are randomly selected. According to their habits of booking rooms at Airbnb and taking those houses as an example, we illustrate how to select a recommendation alternative using the proposed method in this paper.

Step 1. According to requirements of users, the absolute frequency matrix is shown in Table 3.

The corresponding requirement relative frequency matrix is shown in Table 4.

The alternative is evaluated by experts based on the required attributes of users (https://share.weiyun.com/5J3 $\mathrm{KcW} 8$ ), and the corresponding probabilistic hesitant fuzzy evaluation matrix is obtained which is shown in Table 5.
Table 1 Influence factor
Unique stays $\left(C_{1}\right)$

Available for whole family $\left(C_{2}\right)$

Entire house $\left(C_{3}\right)$

Service facilities $\left(C_{4}\right)$

Domestic services $\left(C_{5}\right)$

Basic services $\left(C_{6}\right)$

Convenient transportation $\left(C_{7}\right)$

Low rent $\left(C_{8}\right)$
Some very special residences, such as castle, hut, camper, etc.

Suitable for family travel, can accommodate at least three people

Have a place to yourself, no area shared with others

Shopping malls, banks, hospitals, and other places nearby

Free parking, gymnasium, swimming pool, and more

Kitchen, separate toilet, heating, hair dryer, wireless Internet, smoke alarm, and other infrastructure

The location is close to the airport, train station, subway station, bus station, etc.

The price is lower than the average nightly price in the search area
Step 2. Calculate the satisfaction degree of PHFE according to Eq. (14), and they are shown in Table 6.

Step 3. We establish bipartite network between users and alternatives based on PHFEs. Users' requirements for attributes and the satisfaction degree of PHFEs are considered simultaneously. Specific steps of recommendation method are as follows: 
Table 2 House information

\begin{tabular}{|c|c|c|c|c|c|c|}
\hline \multirow[t]{2}{*}{ Attributes } & \multirow[t]{2}{*}{ Characteristics } & \multicolumn{5}{|c|}{ Alternatives } \\
\hline & & $\overline{A_{1}}$ & $A_{2}$ & $A_{3}$ & $A_{4}$ & $\overline{A_{5}}$ \\
\hline$C_{1}$ & Unique stays & $x$ & $x$ & $\sqrt{ }$ & $x$ & $x$ \\
\hline \multirow[t]{3}{*}{$C_{2}$} & Available for three guests & $\sqrt{ }$ & $\sqrt{ }$ & $\sqrt{ }$ & $\sqrt{ }$ & $x$ \\
\hline & At least two standard beds & $x$ & $\sqrt{ }$ & $x$ & $x$ & $x$ \\
\hline & Available for at least four people & $x$ & $\sqrt{ }$ & $\sqrt{ }$ & $x$ & $x$ \\
\hline \multirow[t]{3}{*}{$C_{3}$} & Entire house & $\sqrt{ }$ & $\sqrt{ }$ & $\sqrt{ }$ & $x$ & $x$ \\
\hline & Private room & $\sqrt{ }$ & $\sqrt{ }$ & $\sqrt{ }$ & $\sqrt{ }$ & $\times$ \\
\hline & Shared room & $x$ & $x$ & $x$ & $\sqrt{ }$ & $\sqrt{ }$ \\
\hline \multirow[t]{3}{*}{$C_{4}$} & Shopping mall & $\times$ & $\sqrt{ }$ & $\times$ & $\sqrt{ }$ & $\times$ \\
\hline & Free parking & $x$ & $\sqrt{ }$ & $\sqrt{ }$ & $\sqrt{ }$ & $\sqrt{ }$ \\
\hline & Bank or hospital & $x$ & $\sqrt{ }$ & $x$ & $\sqrt{ }$ & $x$ \\
\hline \multirow[t]{2}{*}{$C_{5}$} & Garden & $x$ & $x$ & $\sqrt{ }$ & $x$ & $x$ \\
\hline & Pool or Gym & $x$ & $x$ & $x$ & $x$ & $x$ \\
\hline \multirow[t]{3}{*}{$C_{6}$} & Kitchen & $x$ & $\sqrt{ }$ & $x$ & $x$ & $x$ \\
\hline & Private bathroom & $\sqrt{ }$ & $\sqrt{ }$ & $x$ & $x$ & $x$ \\
\hline & Hair dryer, wireless network, smoke detector & $\sqrt{ }$ & $\sqrt{ }$ & $\sqrt{ }$ & $\sqrt{ }$ & $\sqrt{ }$ \\
\hline \multirow[t]{3}{*}{$C_{7}$} & Subway station, bus station & $\sqrt{ }$ & $\sqrt{ }$ & $\times$ & $\sqrt{ }$ & $\sqrt{ }$ \\
\hline & Airport & $x$ & $x$ & $\sqrt{ }$ & $x$ & $x$ \\
\hline & Railway station & $x$ & $\sqrt{ }$ & $x$ & $\sqrt{ }$ & $\sqrt{ }$ \\
\hline \multirow[t]{3}{*}{$C_{8}$} & Less than the $30 \%$ of nightly average price in the search area & $x$ & $x$ & $x$ & $x$ & $\sqrt{ }$ \\
\hline & $\begin{array}{l}\text { Less than the nightly average price } \\
\text { Average price houses in the search area }\end{array}$ & $\sqrt{ }$ & $x$ & $x$ & $\sqrt{ }$ & $\sqrt{ }$ \\
\hline & $\begin{array}{l}\text { Higher than the nightly average price } \\
\text { Average price houses in the search area }\end{array}$ & $x$ & $x$ & $x$ & $x$ & $\times$ \\
\hline
\end{tabular}

Table 3 The absolute frequency matrix

\begin{tabular}{lrrrr}
\hline Users & $U_{1}$ & $U_{2}$ & $U_{3}$ & $U_{4}$ \\
\hline Total booking number & 23 & 47 & 82 & 61 \\
Unique stays $\left(C_{1}\right)$ & 0 & 0 & 50 & 0 \\
Available for whole family $\left(C_{2}\right)$ & 0 & 15 & 0 & 48 \\
Entire house $\left(C_{3}\right)$ & 0 & 0 & 36 & 58 \\
Service facilities $\left(C_{4}\right)$ & 0 & 36 & 0 & 32 \\
Domestic services $\left(C_{5}\right)$ & 0 & 0 & 68 & 0 \\
Basic services $\left(C_{6}\right)$ & 23 & 35 & 75 & 22 \\
Convenient transportation $\left(C_{7}\right)$ & 15 & 16 & 0 & 0 \\
Low rent $\left(C_{8}\right)$ & 19 & 0 & 0 & 0 \\
\hline
\end{tabular}

First, determine the set of adjacent edges according to Eq. (18):

$$
\begin{gathered}
\Gamma=\{o(1,1), o(1,4), o(1,5), o(2,1), o(2,2), o(2,3), \\
o(2,4), o(3,3), o(4,1), o(4,2), o(4,3), o(4,4)\} .
\end{gathered}
$$

Then, calculate the weight of adjacent edge according to Eq. (19) as shown in Table 7.

Step 4. In the established bipartite graph network, the recommended user $U_{3}$ was filled with gray. If the alternatives
Table 4 The relative frequency matrix

\begin{tabular}{lllll}
\hline Users & $U_{1}$ & $U_{2}$ & $U_{3}$ & $U_{4}$ \\
\hline Total frequency & 1 & 1 & 1 & 1 \\
Unique stays $\left(C_{1}\right)$ & 0 & 0 & 0.22 & 0 \\
Available for whole family $\left(C_{2}\right)$ & 0 & 0.15 & 0 & 0.30 \\
Entire house $\left(C_{3}\right)$ & 0 & 0 & 0.16 & 0.36 \\
Service facilities $\left(C_{4}\right)$ & 0 & 0.35 & 0 & 0.20 \\
Domestic services $\left(C_{5}\right)$ & 0 & 0 & 0.30 & 0 \\
Basic services $\left(C_{6}\right)$ & 0.40 & 0.34 & 0.32 & 0.14 \\
Convenient transportation $\left(C_{7}\right)$ & 0.26 & 0.16 & 0 & 0 \\
Low rent $\left(C_{8}\right)$ & 0.34 & 0 & 0 & 0 \\
\hline
\end{tabular}

have been connected with user $U_{3}$, its initial resource would be assigned a unit resource, otherwise zero. As shown in Fig. 5a, initial resource of alternative $A_{3}$ is 1 , and initial resource of the other alternatives is 0 . First, the resource flows from alternative to user, and the resource allocation is shown in Fig. 5b. Then, resource flows back to alternative, and the resource allocation is shown in Fig. 5c.

It is easy to see from Fig. 5 that $g\left(U_{h}\right)=g\left(U_{4}\right)$ and $F$ $\left(A_{o}\right)=f^{\prime}\left(A_{2}\right)$. 
Table 5 Probabilistic hesitant fuzzy evaluation matrix

\begin{tabular}{|c|c|c|c|c|}
\hline & $C_{1}$ & $C_{2}$ & $C_{3}$ & $C_{4}$ \\
\hline$A_{1}$ & $\{0\}$ & $\{0.2(0.7), 0.5(0.1), 0.8(0.2)\}$ & $\{1\}$ & $\{0.2(0.4), 0.3(0.6)\}$ \\
\hline$A_{2}$ & $\{0\}$ & $\{0.9(0.6), 0.4(0.2), 0.6(0.3)\}$ & $\{1\}$ & $\{0.8(0.8), 0.9(0.1), 1(0.1)\}$ \\
\hline$A_{3}$ & $\{1\}$ & $\{0.3(0.5), 0.6(0.5)\}$ & $\{1\}$ & $\{0.3(0.7), 0.2(0.3)\}$ \\
\hline$A_{4}$ & $\{0\}$ & $\{0.8(0.2), 0.5(0.6), 0.6(0.2)\}$ & $\{0.5(0.6), 0.6(0.4)\}$ & $\{0.8(0.4), 0.9(0.5)\}$ \\
\hline \multirow[t]{2}{*}{$A_{5}$} & $\{0\}$ & $\{0\}$ & $\{0\}$ & $\{0.4(0.6), 0.3(0.4)\}$ \\
\hline & $C_{5}$ & $C_{6}$ & $C_{7}$ & $C_{8}$ \\
\hline$A_{1}$ & $\{0\}$ & $\{0.6(0.4), 0.7(0.6)\}$ & $\{0.6(0.4), 0.9(0.2), 0.5(0.4)\}$ & $\{0.5(0.6), 0.6(0.3), 0.8(0.1)\}$ \\
\hline$A_{2}$ & $\{0\}$ & $\{0.8(0.9), 0.9(0.1)\}$ & $\{0.9(0.8), 0.4(0.2)\}$ & $\{0\}$ \\
\hline$A_{3}$ & $\{0.7(0.4), 0.9(0.6)\}$ & $\{0.5(0.8), 0.4(0.2)\}$ & $\{0.1(0.9), 0.2(0.1)\}$ & $\{0\}$ \\
\hline$A_{4}$ & $\{0\}$ & $\{0.4(0.7), 0.3(0.2), 0.1(0.1)\}$ & $\{0.9(0.6), 0.8(0.1), 0.7(0.3)\}$ & $\{0.9(0.8), 0.8(0.2)\}$ \\
\hline$A_{5}$ & $\{0\}$ & $\{0.2(0.9), 0.1(0.1)\}$ & $\{0.9(0.4), 0.8(0.4), 0.7(0.2)\}$ & $\{1\}$ \\
\hline
\end{tabular}

Table 6 The satisfaction degree of PHFE

\begin{tabular}{lllllllll}
\hline & $C_{1}$ & $C_{2}$ & $C_{3}$ & $C_{4}$ & $C_{5}$ & $C_{6}$ & $C_{7}$ & $C_{8}$ \\
\hline$A_{1}$ & 0 & 0.30 & 1 & 0.25 & 0 & 0.53 & 0.41 & 0.39 \\
$A_{2}$ & 0 & 0.41 & 1 & 0.38 & 0 & 0.53 & 0.52 & 0 \\
$A_{3}$ & 1 & 0.40 & 1 & 0.26 & 0.55 & 0.41 & 0.11 & 0 \\
$A_{4}$ & 0 & 0.40 & 0.47 & 0.59 & 0 & 0.29 & 0.59 & 0.57 \\
$A_{5}$ & 0 & 0 & 0 & 0.34 & 0 & 0.18 & 0.43 & 1 \\
\hline
\end{tabular}

Table 7 The weight matrix of adjacent edges

\begin{tabular}{llllll}
\hline & $A_{1}$ & $A_{2}$ & $A_{3}$ & $A_{4}$ & $A_{5}$ \\
\hline$U_{1}$ & 0.45 & 0 & 0 & 0.46 & 0.52 \\
$U_{2}$ & 0.38 & 0.47 & 0.22 & 0.46 & 0 \\
$U_{3}$ & 0 & 0 & 0.68 & 0 & 0 \\
$U_{4}$ & 0.57 & 0.65 & 0.54 & 0.45 & 0 \\
\hline
\end{tabular}

Step 5. Finally, it is prior to recommend alternative $A_{2}$ for user $U_{3}$. Because user $U_{3}$ is similar to user $U_{4}$ and user $U_{4}$ gives a high evaluation for alternative $A_{2}$.

Step 6. End.

\section{Comparative analysis}

\section{Comparison analysis with the bipartite network projection recommendation method}

Personalized recommendation method based on resource allocation was first introduced by Zhou et al. [19]. They proposed recommending objects to users in accordance with resource allocation. In what follows, we use bipartite projection network personal recommendation method to recommend a suitable accommodation for user $U_{3}$.
The bipartite network between users and alternatives is established and shown in Fig. 6.

As shown in Fig. 6, the final resources obtained by each program are:

$A_{1}=4 / 27, A_{2}=2 / 9, A_{3}=13 / 27, A_{4}=4 / 27, A_{5}=0$.

Obviously, alternative $A_{2}$ obtained maximum resources, so alternative $A_{2}$ is the prior alternative which is recommended to users $U_{3}$. However, it is worth noting that if the recommended content is determined according to the final resource allocation, and the resources obtained by the alternative $A_{1}$ and alternative $A_{4}$ are equal. In fact, from Table 3 , it can be seen that the user $U_{3}$ have a requirement of attributes $C_{1}, C_{3}, C_{5}$, and $C_{6}$. Obviously, alternative $A_{1}$ and alternative $A_{4}$ have different degree of satisfying those attributes, which implies that the resources obtained by the two alternatives should be different. The main reason is that the calculating method for the edge weight is not reasonable, and thus, it cannot be used to determine the edge weight.

\section{Comparison analysis with the method based on score values of PHFEs}

Pan et al. [22] defined the weight of edges based on the distribution of degree between user and object. In most cases, users do not directly express their preferences for objects, but give their demand. Our method can deal with this situation effectively. To satisfy user's requirement, we use the evaluation information of experts to determine the possible election of users. Not only that a novel edge weight calculation method based on satisfaction degree of alternatives is proposed in this paper. This method takes uncertainty of recommendation decision information into consideration. To prove the validity of the proposed method, a comparison with 


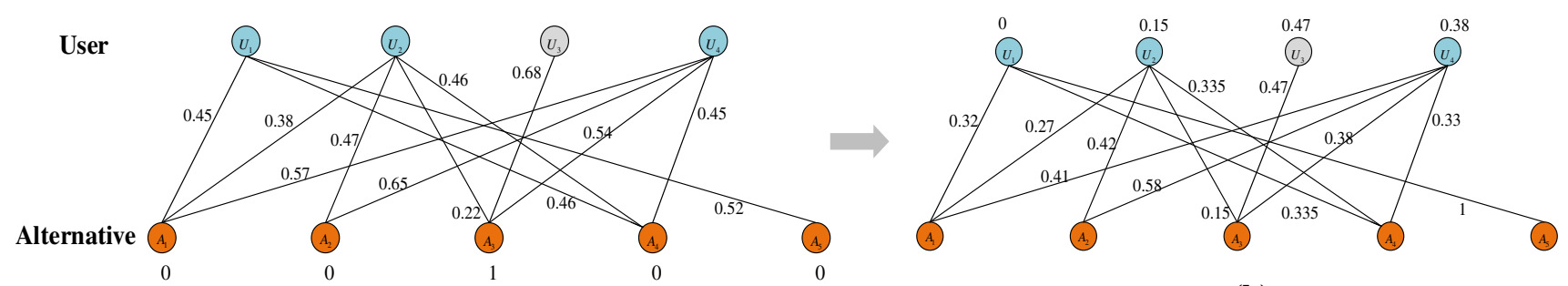

(a)

(b)

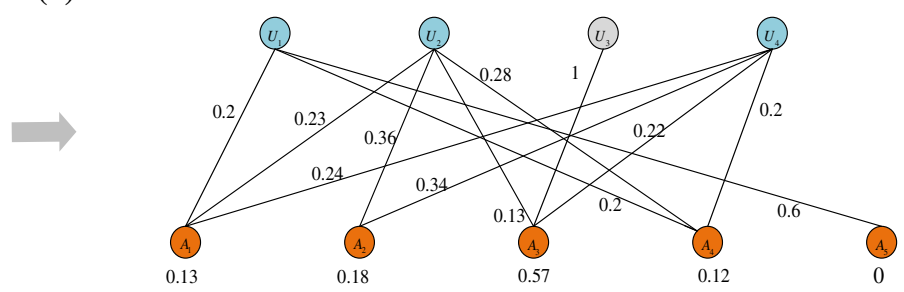

(c)

Fig. 5 Bipartite network projection based on satisfaction degree of PHFEs

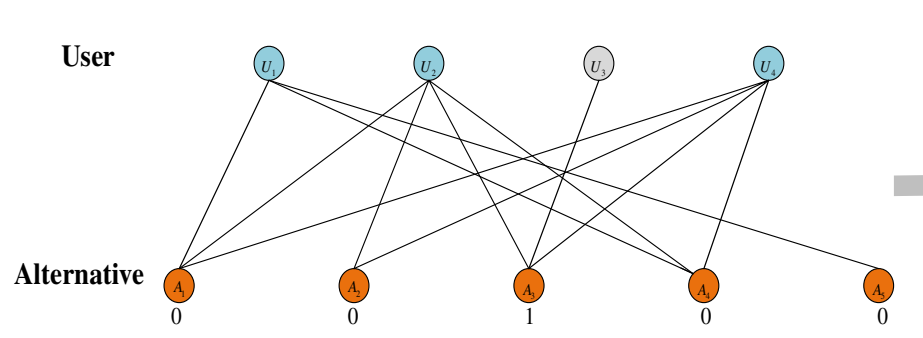

(a)

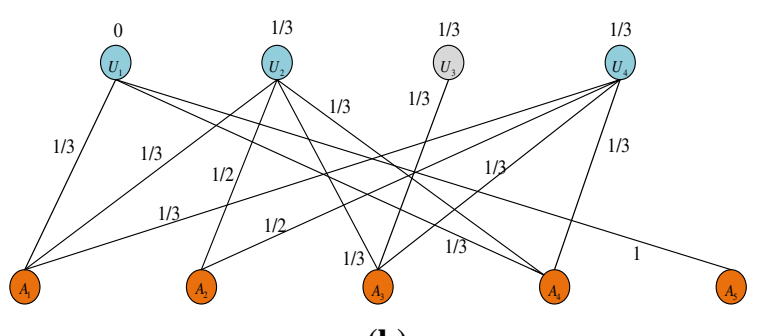

(b)

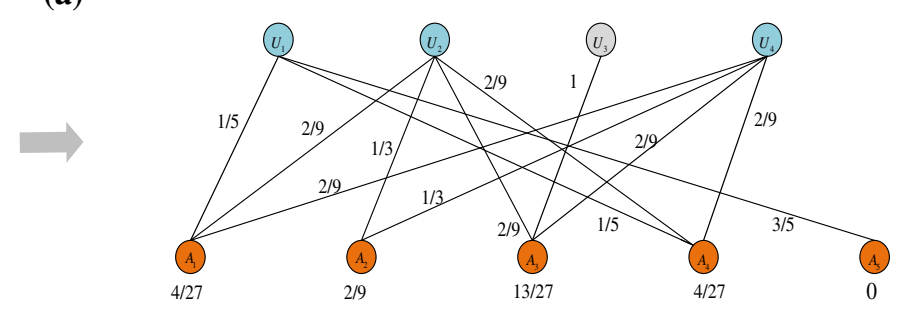

(c)

Fig. 6 Bipartite network projection personal recommendation

the edge weight calculating method based on score function of alternatives is conducted in the following.

Step 1. According to requirements of users, the absolute frequency matrix is obtained and shown in Table 3.

Step 2. We calculate the score values of PHFEs in Table 5, and the results are shown in Table 8.

The value in $i$ th row and $j$ th column is the score of PHFE, where the score can be calculated by Eq. (3).

Step 3. First, determine the set of adjacent edges according to Eq. (18):

$$
\begin{gathered}
\Gamma=\{o(1,1), o(1,4), o(1,5), o(2,1), o(2,2), o(2,3), \\
o(2,4), o(3,3), o(4,1), o(4,2), o(4,3), o(4,4)\} .
\end{gathered}
$$

Table 8 The score value matrix of alternatives

\begin{tabular}{lllllllll}
\hline & $C_{1}$ & $C_{2}$ & $C_{3}$ & $C_{4}$ & $C_{5}$ & $C_{6}$ & $C_{7}$ & $C_{8}$ \\
\hline$A_{1}$ & 0 & 0.35 & 1 & 0.26 & 0 & 0.66 & 0.62 & 0.6 \\
$A_{2}$ & 0 & 0.8 & 1 & 0.74 & 0 & 0.81 & 0.8 & 0 \\
$A_{3}$ & 1 & 0.45 & 1 & 0.27 & 0.82 & 0.48 & 0.11 & 0 \\
$A_{4}$ & 0 & 0.58 & 0.54 & 0.77 & 0 & 0.35 & 0.83 & 0.9 \\
$A_{5}$ & 0 & 0 & 0 & 0.36 & 0 & 0.19 & 0.82 & 1 \\
\hline
\end{tabular}

Then, the weight of adjacent edge $\phi_{k i}$ between alternative $A_{i}(i=1,2, \ldots, n)$ and user $U_{k}(k=1,2 \ldots, s)$ can be calculated by $\phi_{k i}=\sum_{j=1}^{m} E_{k j} \varphi_{i j}$, where $E_{k j}$ is the score value in Table 8. The weights of adjacent edge are shown in Table 9. 
Table 9 The weight matrix of adjacent edges

\begin{tabular}{llllll}
\hline & $A_{1}$ & $A_{2}$ & $A_{3}$ & $A_{4}$ & $A_{5}$ \\
\hline$U_{1}$ & 0.45 & 0 & 0 & 0.46 & 0.52 \\
$U_{2}$ & 0.38 & 0.47 & 0.22 & 0.46 & 0 \\
$U_{3}$ & 0 & 0 & 0.68 & 0 & 0 \\
$U_{4}$ & 0.57 & 0.65 & 0.54 & 0.45 & 0 \\
\hline
\end{tabular}

Step 4. We establish bipartite network between users and alternatives based on PHFEs. According to Eqs. (20) and (21), the final projection result is shown in Fig. 7.

It is easy to see from Fig. 7 that $g\left(U_{h}\right)=g\left(U_{4}\right)$ and $F$ $\left(A_{o}\right)=f^{\prime}\left(A_{2}\right)$.

Step 5. It is prior to recommend alternative $A_{2}$ for user $U_{3}$. Because user $U_{3}$ is similar to user $U_{4}$ and user $U_{4}$ gives a high evaluation for alternative $A_{2}$.

Step 6. End.

We can find that the result is the same as that by our proposed method, which implies that the proposed method is reasonable. Different from the edge weight determination method based on score values of PHFE, the proposed method takes the deviation degree of decision-makers into account, which makes the results more comprehensive and reliable.

\section{Comparison analysis with recommendation decision-making algorithm based on HFSs and bipartite network projection}

To further explicate the superiority of using PHFSs, we make a comparison with the algorithm based on HFSs and bipartite network projection. Correspondingly, the hesitant fuzzy satisfaction degree in reference [54] is used to calculate the adjacent weights.

Step 1. According to requirements of users, the absolute frequency matrix is shown in Table 3 . The corresponding requirement relative frequency matrix is shown in Table 4 . The alternative is evaluated by experts based on the required attributes of users, and the corresponding hesitant fuzzy evaluation matrix is obtained which is shown in Table 10.

Step 2. Calculate the satisfaction degree of HFE, and the satisfaction degree matrix can be derived, which is shown in Table 11.

Step 3. We establish bipartite network between users and alternatives based on HFEs. Users' requirements for attributes and the satisfaction degree of HFEs are considered simultaneously. Specific steps of recommendation method are as follows:

First, determine the set of adjacent edges according to Eq. (18):

$$
\begin{gathered}
\Gamma=\{o(1,1), o(1,4), o(1,5), o(2,1), o(2,2), o(2,3), \\
o(2,4), o(3,3), o(4,1), o(4,2), o(4,3), o(4,4)\} .
\end{gathered}
$$

Then, calculate the weight of adjacent edge according to Eq. (19) as shown in Table 12.

Step 4. In the established bipartite graph network, the recommended user $U_{3}$ was filled with gray. If the alternatives have been connected with user $U_{3}$, its initial resource would be assigned a unit resource, otherwise zero. As shown in Fig. 8a, initial resource of alternative $A_{3}$ is 1 , and initial resource of the other alternatives is 0 . First, the resource flows from alternative to user, and the resource allocation is shown

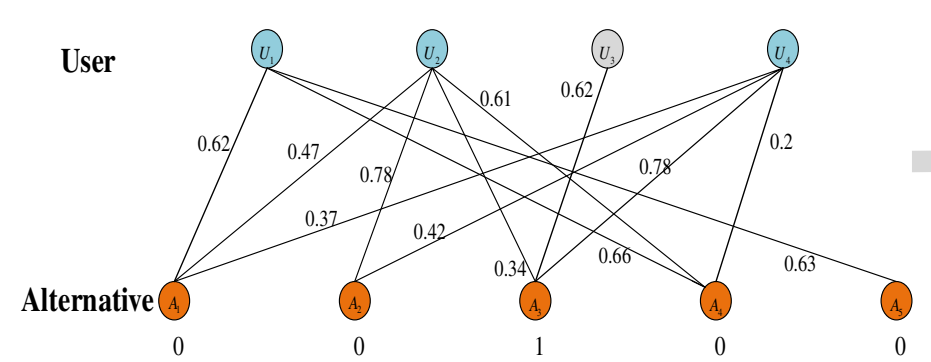

(a)

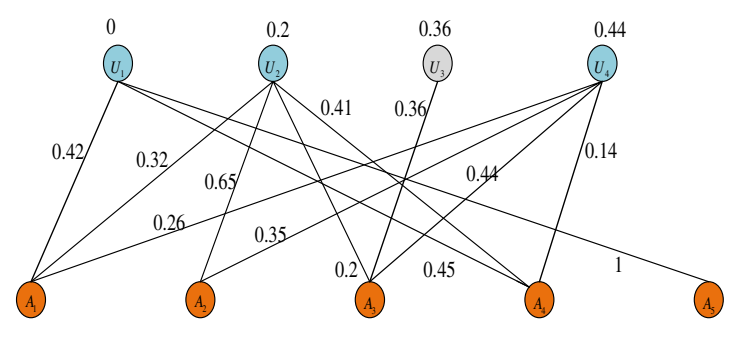

(b)

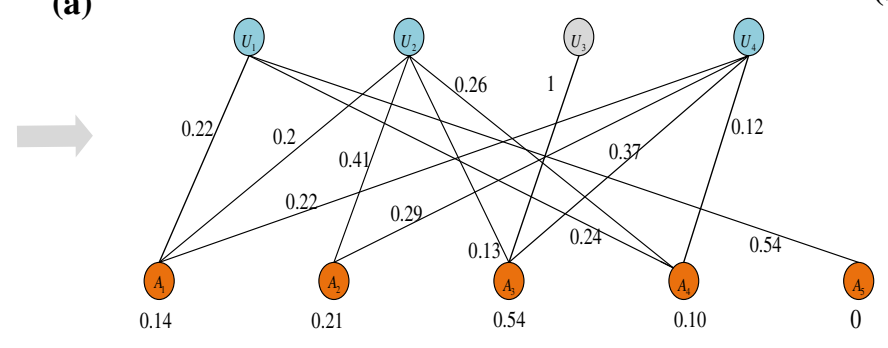

(c)

Fig. 7 Bipartite network projection based on score values of PHFEs 
Table 10 Hesitant fuzzy evaluation matrix

\begin{tabular}{lllllllll}
\hline & $C_{1}$ & $C_{2}$ & $C_{3}$ & $C_{4}$ & $C_{5}$ & $C_{6}$ & $C_{7}$ & $C_{8}$ \\
\hline$A_{1}$ & $\{0\}$ & $\{0.2,0.5,0.8\}$ & $\{1\}$ & $\{0.2,0.3\}$ & $\{0\}$ & $\{0.6,0.7\}$ & $\{0.6,0.9,0.5\}$ & $\{0.5,0.6,0.8\}$ \\
$A_{2}$ & $\{0\}$ & $\{0.9,0.4,0.6\}$ & $\{1\}$ & $\{0.8,0.9,1\}$ & $\{0\}$ & $\{0.8,0.9\}$ & $\{0.9,0.4\}$ & $\{0\}$ \\
$A_{3}$ & $\{1\}$ & $\{0.3,0.6\}$ & $\{1\}$ & $\{0.3,0.2\}$ & $\{0.7,0.9\}$ & $\{0.5,0.4\}$ & $\{0.1,0.2\}$ & $\{0\}$ \\
$A_{4}$ & $\{0\}$ & $\{0.8,0.5,0.6\}$ & $\{0.5,0.6\}$ & $\{0.8,0.9\}$ & $\{0\}$ & $\{0.4,0.3,0.1\}$ & $\{0.9,0.8,0.7\}$ & $\{0.9,0.8\}$ \\
$A_{5}$ & $\{0\}$ & $\{0\}$ & $\{0\}$ & $\{0.4,0.3\}$ & $\{0\}$ & $\{0.2,0.1\}$ & $\{0.9,0.8,0.7\}$ & $\{1\}$ \\
\hline
\end{tabular}

Table 11 The satisfaction degree matrix of evaluation information

\begin{tabular}{lllllllll}
\hline & $C_{1}$ & $C_{2}$ & $C_{3}$ & $C_{4}$ & $C_{5}$ & $C_{6}$ & $C_{7}$ & $C_{8}$ \\
\hline$A_{1}$ & 0 & 0.42 & 1 & 0.24 & 0 & 0.62 & 0.60 & 0.56 \\
$A_{2}$ & 0 & 0.53 & 1 & 0.87 & 0 & 0.81 & 0.52 & 0 \\
$A_{3}$ & 1 & 0.39 & 1 & 0.24 & 0.73 & 0.43 & 0.14 & 0 \\
$A_{4}$ & 0 & 0.56 & 0.52 & 0.81 & 0 & 0.24 & 0.78 & 0.81 \\
$A_{5}$ & 0 & 0 & 0 & 0.33 & 0 & 0.14 & 0.78 & 1 \\
\hline
\end{tabular}

Table 12 The weight matrix of adjacent edges

\begin{tabular}{llllll}
\hline & $A_{1}$ & $A_{2}$ & $A_{3}$ & $A_{4}$ & $A_{5}$ \\
\hline$U_{1}$ & 0.59 & 0 & 0 & 0.57 & 0.60 \\
$U_{2}$ & 0.45 & 0.74 & 0.31 & 0.57 & 0 \\
$U_{3}$ & 0 & 0 & 0.59 & 0 & 0 \\
$U_{4}$ & 0.36 & 0.42 & 0.74 & 0.16 & 0 \\
\hline
\end{tabular}

in Fig. 8b. Then, resource flows back to alternative, and the resource allocation is shown in Fig. 8c.

It is easy to see from Fig. 8 that $g\left(U_{h}\right)=g\left(U_{4}\right)$ and $F$ $\left(A_{o}\right)=f^{\prime}\left(A_{2}\right)$.
Step 5. It is prior to recommend alternative $A_{2}$ for user $U_{3}$. Because user $U_{3}$ is similar to user $U_{4}$ and user $U_{4}$ gives a high evaluation for alternative $A_{2}$.

Step 6. End.

We can find that the result is the same as that by the proposed method, which implies that the proposed method is effective and reasonable. However, as an extension of HFSs, PHFSs contains not only the different membership degrees but also the occurrence probabilities associated with the membership degrees, which reserves more original information than HFSs. Therefore, our method can describe uncertainty of decision-making information better.

\section{Conclusion}

Based on users' decision-making information and experts' evaluation information, a bipartite network between users and alternatives is established in this paper. And a probabilistic hesitant fuzzy recommendation decision-making method based on bipartite network projection is proposed. The proposed method is utilized to recommend accommodation for Airbnb users in this paper. It is worth mentioning that the satisfaction degree of PHFE is applied to calculate the edge weight of bipartite network. And the priority recommenda-

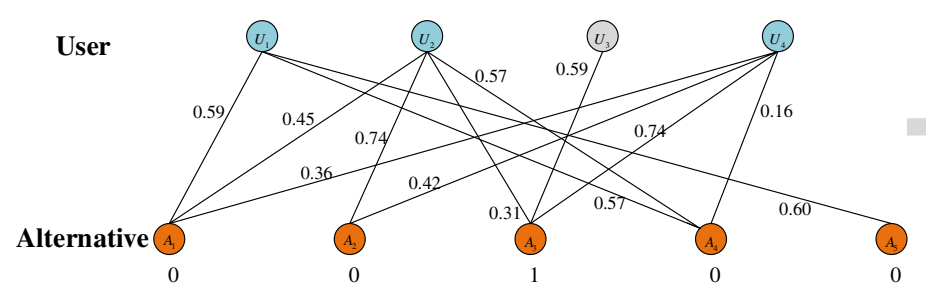

(a)

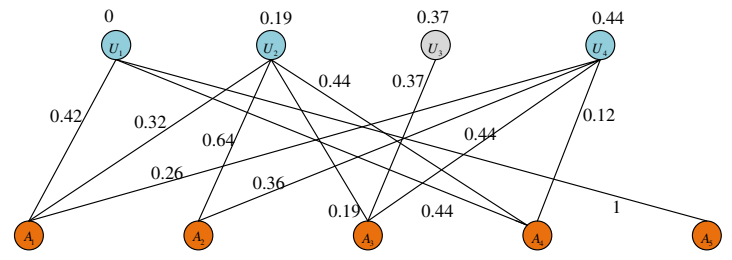

(b)

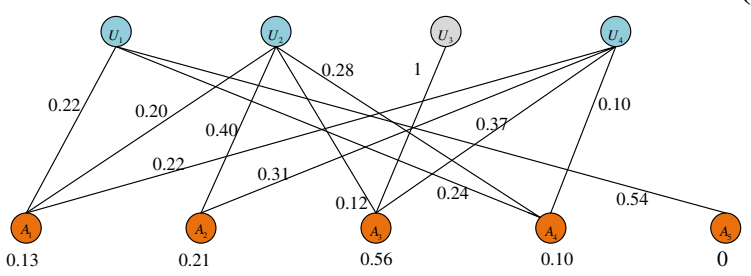

(c)

Fig. 8 Bipartite network projection based on satisfaction degree of HFEs 
tion of alternative is determined by the resource allocation. We consider the uncertainties of recommendation decisionmaking information and catch the root cause of users' choice. Thus, a more reasonable recommendation result could be obtained by our method.

In future research, we will continue to focus on bipartite network projection, and expand the application fields of the proposed method, such as online book recommendation, gourmet recommendation, and so on. In addition, we will extend the proposed method to accommodate probabilistic dual hesitant fuzzy or probabilistic linguistic environments, and apply the proposed method to pattern recognition and online reviews.

Acknowledgements This work was supported by the National Natural Science Foundation of China (No. 71601002), the Humanities and Social Sciences Foundation of Ministry of Education of China (Nos. 16YJC630077 and 18YJC630249), the Foundation for Young Talents in College of Anhui Province (No. gxyqZD2018033), the major project of Humanities and Social Sciences of Ministry of Education of China (No. 16JJD840008), the Anhui Provincial Natural Science Foundation (No. 1708085MG168) and Provincial Humanities and Social Science Research Project of Anhui Colleges (No. SK2018A0605).

Open Access This article is licensed under a Creative Commons Attribution 4.0 International License, which permits use, sharing, adaptation, distribution and reproduction in any medium or format, as long as you give appropriate credit to the original author(s) and the source, provide a link to the Creative Commons licence, and indicate if changes were made. The images or other third party material in this article are included in the article's Creative Commons licence, unless indicated otherwise in a credit line to the material. If material is not included in the article's Creative Commons licence and your intended use is not permitted by statutory regulation or exceeds the permitted use, you will need to obtain permission directly from the copyright holder. To view a copy of this licence, visit http://creativecomm ons.org/licenses/by/4.0/.

\section{References}

1. China National Information Center Sharing Economy Research Center (2019) Report on the development of sharing accommodation in China 2019

2. China National Information Center Sharing Economy Research Center (2018) Report on the development of sharing accommodation in China

3. Rashidi M, Hussin ARC, Nilashi M (2015) Entropy-based ranking approach for enhancing diversity in tag-based community recommendation. J Soft Comput Decis Support Syst 3(1):1-7

4. Pozna C, Precup RE, Tar JK, Škrjanc I, Preitl S (2010) New results in modelling derived from Bayesian filtering. Knowl Based Syst 23(2):182-194

5. Nilashi M, Ibrahim O, Yadegaridehkordi E, Samad S, Akbari E, Alizadeh A (2018) Travelers decision making using online review in social network sites: a case on TripAdvisor. J Comput Sci 28:168-179

6. Pazzani MJ, Billsus D (2007) Content-based recommendation systems. The adaptive web. Springer, Berlin, pp 325-341

7. Liang X, Liu P, Wang Z (2019) Hotel selection utilizing online reviews: a novel decision support model based on sentiment analysis and DL-VIKOR method. Technol Econ Dev Econ 25(6):1139-1161

8. Liu Y, Bi JW, Fan ZP (2017) Ranking products through online reviews: a method based on sentiment analysis technique and intuitionistic fuzzy set theory. Inf Fusion 36:149-161

9. Lind PG, Gonzalez MC, Herrmann HJ (2005) Cycles and clustering in bipartite networks. Phys Rev E 72(5):056127

10. Zhang D, Xie F, Wang D, Zhang Y, Sun Y (2014) Cluster analysis based on bipartite network. Math Probl Eng

11. Chessa A, Crimaldi I, Riccaboni M, Trapin L (2014) Cluster analysis of weighted bipartite networks: a new copula-based approach. PLoS One 9(10):e109507

12. Guimerà R, Sales-Pardo M, Amaral LAN (2007) Module identification in bipartite and directed networks. Phys Rev E 76(3):036102

13. Barber MJ (2007) Modularity and community detection in bipartite networks. Phys Rev E 76(6):066102

14. Sarma KK (2009) Neural network based feature extraction for assamese character and numeral recognition. Int $\mathbf{J}$ Artif Intell 2(S09):37-56

15. Lambiotte R, Ausloos M (2005) Uncovering collective listening habits and music genres in bipartite networks. Phys Rev E 72(6):066107

16. Grujić J (2008) Movies recommendation networks as bipartite graphs. In: International conference on computational science (pp 576-583). Springer, Berlin, Heidelberg

17. Yin F, Zhao X, Zhang X, Ge B, Xiao W (2014) Improving accuracy and scalability of personal recommendation based on bipartite network projection. Math Probl Eng

18. Zhai X, Hu H, Hu G, Qu Y (2019) PRBL: a personalized recommendation system based on bipartite network projection and link community detection. In: Proceedings of the ACM turing celebration conference-China (p 150). ACM

19. Zhou T, Ren J, Medo M, Zhang YC (2007) Bipartite network projection and personal recommendation. Phys Rev E 76(4):046115

20. Liu J, Shang M, Chen D (2009) Personal recommendation based on weighted bipartite networks. In: FSKD 2009, sixth international conference on fuzzy systems and knowledge discovery, Tianjin, China, 14-16 August 2009, 6 volumes. IEEE

21. Wang J, Shao FJ, Wu SY, Sun RC (2016) Weighted bipartite network projection for personalized recommendations. J Adv Comput Netw 4(1):64

22. Pan X, Deng G, Liu JG (2010) Weighted bipartite network and personalized recommendation. Phys Proced 3(5):1867-1876

23. Li Z, Luo Q, Shi L (2016) Weighted bipartite network recommendation algorithm based on increasing similarity coefficient. Comput Sci 43(7):259-264

24. Song W, Shao P, Liu P (2019) Hybrid recommendation algorithm based on weighted bipartite graph and logistic regression. In: International CCF conference on artificial intelligence (pp 159-170). Springer, Singapore

25. Zadeh LA (1965) Fuzzy sets. Inf Control 8(3):338-353

26. Gil RA, Johanyák ZC, Kovács T (2018) Surrogate model based optimization of traffic lights cycles and green period ratios using microscopic simulation and fuzzy rule interpolation. Int J Artif Intell 16(1):20-40

27. Turksen IB (1986) Interval valued fuzzy sets based on normal forms. Fuzzy Sets Syst 20(2):191-210

28. Kutlu F, Atan Ö, Silahtar O (2020) Intuitionistic fuzzy adaptive sliding mode control of nonlinear systems. Soft Comput 24(1):53-64

29. Atanassov KT (1986) Intuitionistic fuzzy sets. Fuzzy Sets Syst 20:87-96

30. Castillo O, Kutlu F, Atan Ö (2020) Intuitionistic fuzzy control of twin rotor multiple input multiple output systems. J Intell Fuzzy Syst 38(1):821-833

31. Mendel JM, John RB (2002) Type-2 fuzzy sets made simple. IEEE Trans Fuzzy Syst 10(2):117-127 
32. Castillo O, Melin P, Pedrycz W (2011) Design of interval type2 fuzzy models through optimal granularity allocation. Appl Soft Comput 11(8):5590-5601

33. Miyamoto S (2005) Remarks on basics of fuzzy sets and fuzzy multisets. Fuzzy Sets Syst 156(3):427-431

34. Yager RR (2013) Pythagorean fuzzy subsets. In: 2013 Joint IFSA world congress and NAFIPS annual meeting (IFSA/NAFIPS) (pp 57-61). IEEE

35. Garg H (2016) A novel correlation coefficients between Pythagorean fuzzy sets and its applications to decision-making processes. Int J Intell Syst 31(12):1234-1252

36. Torra V (2010) Hesitant fuzzy sets. Int J Intell Syst 25(6):529-539

37. Vij S, Jain A, Tayal D, Castillo O (2020) Scientometric inspection of research progression in hesitant fuzzy sets. J Intell Fuzzy Syst 38(1):619-626

38. Garg H, Arora R (2018) Dual hesitant fuzzy soft aggregation operators and their application in decision-making. Cogn Comput 10(5):769-789

39. Zhu B (2014) Decision method for research and application based on preference relation. Southeast University, Nanjing

40. Liu XD, Wang ZW, Zhang ST, Liu JS (2019) A novel approach to fuzzy cognitive map based on hesitant fuzzy sets for modeling risk impact on electric power system. Int J Comput Intell Syst 12(2):842-854

41. Wei GW (2012) Hesitant fuzzy prioritized operators and their application to multiple attribute decision making. Knowl Based Syst $31: 176-182$

42. Lalotra S, Singh S (2020) Knowledge measure of hesitant fuzzy set and its application in multi-attribute decision-making. Comput Appl Math 39(2):1-31

43. Liu XD, Wang ZW, Hetzler A (2017) HFMADM method based on nondimensionalization and its application in the evaluation of inclusive growth. J Bus Econ Manag 18(4):726-744

44. Ren PJ, Xu ZS, Hao ZN (2016) Hesitant fuzzy thermodynamic method for emergency decision making based on prospect theory. IEEE Trans Cybern 47(9):2531-2543

45. Liu XD, Wang ZW, Zhang ST, Liu JS (2019) Analysis of influencing factors in emergency management based on an integrated methodology. Adapt Behav 27(5):331-345

46. Zhang D, Wu C, Liu J (2020) Ranking products with online reviews: a novel method based on hesitant fuzzy set and sentiment word framework. J Oper Res Soc 71(3):528-542

47. Çolak M, Kaya İ, Özkan B, Budak A, Karaşan A (2020) A multi-criteria evaluation model based on hesitant fuzzy sets for blockchain technology in supply chain management. J Intell Fuzzy Syst 38(1):935-946

48. Xu ZS, Zhou W (2017) Consensus building with a group of decision makers under the hesitant probabilistic fuzzy environment. Fuzzy Optim Decis Mak 16(4):481-503

49. Zhang S, Xu ZS, He Y (2017) Operations and integrations of probabilistic hesitant fuzzy information in decision making. Inf Fusion 38:1-11

50. Wu J, Liu XD, Wang ZW, Zhang ST (2018) Dynamic emergency decision-making method with probabilistic hesitant fuzzy information based on GM $(1,1)$ and TOPSIS. IEEE Access 7:7054-7066
51. Ding J, Xu Z, Zhao N (2017) An interactive approach to probabilistic hesitant fuzzy multi-attribute group decision making with incomplete weight information. J Intell Fuzzy Syst 32(3):2523-2536

52. Li J, Wang JQ (2017) An extended QUALIFLEX method under probability hesitant fuzzy environment for selecting green suppliers. Int J Fuzzy Syst 19(6):1866-1879

53. Zhou W, Xu ZS (2017) Group consistency and group decision making under uncertain probabilistic hesitant fuzzy preference environment. Inf Sci 414:276-288

54. Liu XD, Zhu JJ, Zhang ST, Liu SF (2017) Hesitant fuzzy stochastic multiple attribute decision making method based on regret theory and group satisfaction degree. Chin J Manag Sci 25(10):171-178

55. Xu Z (2017) An analysis of the dilemma of Airbnb's Chinese management under the sharing economy. Tour Overv 10:151-153

56. CBNData, Airbnb (2019) Millennial traveler insight Report

57. Quinby D, Gasdia M (2014) Share this! Private accommodation and the rise of the new gen renters. In: Report. PhoCusWright

58. Tussyadiah IP (2015) An exploratory study on drivers and deterrents of collaborative consumption in travel. Information and communication technologies in tourism 2015. Springer, Cham, pp $817-830$

59. Nowak B, Allen T, Rollo J, Lewis V, He L, Chen A, Savino M (2015) Global insight: who will Airbnb hurt more-hotels or OTAs. Morgan Stanley Res 232-244

60. Guttentag D, Smith S, Potwarka L, Havitz M (2018) Why tourists choose Airbnb: a motivation-based segmentation study. J Travel Res 57(3):342-359

61. Guttentag D (2015) Airbnb: disruptive innovation and the rise of an informal tourism accommodation sector. Curr Issues Tour 18(12):1192-1217

62. Liang LJ, Choi HC, Joppe M (2018) Understanding repurchase intention of Airbnb consumers: perceived authenticity, electronic word-of-mouth, and price sensitivity. J Travel Tour Market 35(1):73-89

Publisher's Note Springer Nature remains neutral with regard to jurisdictional claims in published maps and institutional affiliations. 